\title{
IMPACTOS AMBIENTAIS REGISTRADOS NOS ESTUDOS DAS LAVANDERIAS TÊXTEIS DO ARRANJO PRODUTIVO DO AGRESTE PERNAMBUCANO: UMA RELEITURA PELA PERSPECTIVA DA SUSTENTABILIDADE AMBIENTAL
}

\author{
Maria de Fátima da Silva ${ }^{1}$ \\ Almir Silveira Menelau² \\ Ana Regina Bezerra Ribeiro ${ }^{3}$
}

\begin{abstract}
RESUMO
No setor têxtil, as lavanderias ganham destaque pelo uso de grande volume de água e pela variedade e quantidade de produtos químicos utilizados no processo produtivo. Em consequência geram efluentes tóxicos que comprometem o meio ambiente. Neste sentido, o objetivo deste estudo foi levantar os impactos ambientais originados pelas lavanderias têxteis do arranjo produtivo do Agreste Pernambucano a partir da análise em teses, dissertações, monografias e artigos científicos. Como resultado pode-se afirmar que, os efluentes contaminados jogados nas redes pluviais são os principais poluidores dos rios e que são apontados em todos os estudos como causador de impactos ambientais negativos a saúde humana e ao meio ambiente, além da poluição atmosférica, que é resultante da queima da lenha nas caldeiras sem filtros. Concluise que, a atuação das lavanderias têxteis, na região, tem contribuído para o aumento da poluição do ar, do solo e da água.
\end{abstract}

Palavras chaves: Geração de resíduos; Agentes poluentes; Processo Produtivo.

\footnotetext{
${ }^{1}$ Mestra em Administração e Desenvolvimento Rural pela Universidade Federal Rural de Pernambuco - UFRPE. Especialista em Gestão Pública pelo instituto Federal de Pernambuco - IFPE, Bel. em Administração.

${ }^{2}$ Docente do programa de Pós-Graduação em Administração e Desenvolvimento Rural pela Universidade Federal Rural de Pernambuco.

${ }^{3}$ Docente e Coordenadora do programa de Pós-Graduação em Administração e Desenvolvimento Rural pela Universidade Federal Rural de Pernambuco.
} 


\title{
ENVIRONMENTAL IMPACTS RECORDED IN THE STUDIES OF TEXTILE LAUNDRIES OF THE PRODUCTIVE ARRANGEMENT OF THE AGRESTE PERNAMBUCANO: A REREADING FROM THE PERSPECTIVE OF ENVIRONMENTAL SUSTAINABILITY
}

\begin{abstract}
In the textile sector, the laundries gain prominence for the use of large volumes of water and due to the variety and quantity of chemicals consumed in the production process. As a result, they generate toxic effluents that compromise the environment. In this sense, the objective of this study was to raise the environmental impacts originated by the textile laundries located in the productive field in the countryside (Agreste) of Pernambuco state. The research is based on the analysis explored in theses, dissertations, monographs and scientific articles. As a result, contaminated effluents dumped into rainy drains are the main polluters of rivers. They are also pointed out in all studies as causing negative impacts to human health and to the environment. In addition, these polluters collaborate with air pollution that comes from firewood being born in boilers without filters. It is concluded that the performance of textile laundries in the region have contributed to the increase in air, soil and water pollution.
\end{abstract}

Keywords: Waste generation; Polluting agents; Production Process.

\section{INTRODUÇÃO}

Os desequilíbrios ecológicos existentes no mundo, são via de regra, fruto do inadequado relacionamento do homem com os recursos naturais. Além disso, diferentes formas de disposição e o gerenciamento inadequado de resíduos sólidos e líquidos resultantes das ações antrópicas provocam impactos à saúde humana e ambiental, que vêm sendo discutidos ao longo dos anos, com maior ênfase após as Conferências das Nações Unidas sobre Meio Ambiente e Desenvolvimento, ECO-92; Rio+20 (SILVA et al., 2017).

Após esses eventos, as organizações governamentais e sociais intensificaram a busca por soluções para minimizar as alterações no sistema climático, discutindo estratégias para conciliar o desenvolvimento com a conservação e a proteção do ecossistema, conforme constantes dos 17 Objetivos do Desenvolvimento Sustentável (ODS) da Agenda 2030 (BUSS, 2017). 
Com o surgimento do Desenvolvimento Sustentável e com o intuito de que a iniciativa privada adote a esta proposta, foi criado, em 1992, o World Business Council for Sustainable Development (WBCSD) - Conselho Mundial de Negócios para o Desenvolvimento Sustentável, introduzem as seguintes orientações para serem adotadas pouco a pouco pelas empresas: o sistema de qualidade total - ISO 9000; gestão ambiental; certificação ambiental (BS-7750 e Norma ISO 14000) e produtos que sejam detentores de selos verdes (produtos que desde suas origens possuam elevado padrão de comprometimento com questões ambiental) (LEMOS; NASCIMENTO, 1999, p.24).

As atividades industriais são responsabilizadas, muitas vezes, por contaminações e acidentes ambientais, principalmente, pelo acúmulo de matérias primas, insumos, transporte, e disposição inadequada dos resíduos na empresa (FREIRE et al., 2000). Estas condutas representaram ineficiências no processo produtivo, impõem melhoria na gestão dos resíduos, de modo a viabilizar o aumento da produtividade e a diminuição dos impactos ambientais (KIPERSTOK, 2002, p. 72).

Neste entendimento, pode-se afirmar que os resíduos industriais, depois de gerados, necessitam de destino adequado, pois, além de criar potenciais problemas ambientais, também representam perdas de matérias primas e energia, exigindo investimentos significativos em tratamentos para controlar a poluição (PELIZER et al., 2007), assim, pode-se entender que os resíduos quando não são tratados de forma correta, podem levar a destruição de paisagem, fauna e flora (SAIDELLES et al., 2012).

Neste contexto, uma tendência no mercado é representada pela sustentabilidade empresarial que tem como princípio a valorização socioambiental e econômica dentro do ambiente organizacional (MAZZA; FILHO, 2013). Portanto, benefícios econômicos, sociais e ambientais podem ser alcançados por meio do aproveitamento dos resíduos gerados, como por exemplo, a redução dos gastos com acondicionamento e transporte, na criação ou diminuição de aterros, na utilização de menos recursos naturais e na diminuição dos riscos ambientais que esses resíduos podem causar à saúde e à sociedade (BERARDI; BARBIERI, 2013).

As lavanderias de jeans, também chamadas de lavanderias industriais, são segmentos de um grande setor da moda. Essa atividade além de consumir muita 
água, após o processo de lavagem lança resíduos químicos no meio ambiente. Por isso, essa prática requer muita cautela devido ao seu potencial poluidor, o que se justifica, cada vez mais, a necessidade de pesquisas com relação ao reuso da água (BRITO, 2013). Neste entendimento, esta pesquisa tem por objetivo levantar os impactos ambientais originados pelas lavanderias têxteis do APL de confecções do Agreste Pernambucano a partir de estudos publicados entre 2005 a 2018.

\section{REFERENCIAL TEÓRICO}

\subsection{SUSTENTABILIDADE AMBIENTAL NO SETOR TÊXTIL}

A sustentabilidade ambiental no mundo corporativo tem por objetivo modificar os modelos de negócios tradicionais, onde visa-se apenas o lucro, e propõe um novo modelo de gestão de negócios considerando aspectos social, ambiental e econômico (LINS; ZYLBERSZTAJN, 2010). Neste contexto, pode-se afirmar que a sustentabilidade empresarial é pautada pela ação dos agentes na busca entre equilíbrio econômico, social e ambiental. Assim surge a importância de trabalhar com ações sustentáveis na indústria têxtil que é uma das mais antigas do mundo.

No Brasil, a indústria têxtil iniciou sua atividade no período colonial, mas só na década 1940, foi que o setor passou a ser considerado um dos mais importantes para a economia, atuando-se em segundo lugar na produção mundial (COSTA, 2008; KON; COAN, 2009). Com o passar dos anos a indústria têxtil ganhou destaque pelo seu potencial de expansão e aumento no consumo e com isso, também cresceu a concorrência e as exigências socioambientais (MEHLER, 2013).

Oliveira (2008) afirma que para produzir $1 \mathrm{~kg}$ de tecido são necessários de 80 a 150 litros de água, desse montante, $12 \%$ é evaporado durante o processo produtivo e $80 \%$ são desperdiçados. Pode-se entender que os elevados uso de água ocorre nas etapas de beneficiamento dos tecidos como lavagem e tingimento (IMMICH, 2006). Esses processos resultam em impactos ambientais e que necessitam de uma gestão eficiente para minimizar estes danos (NAVACHI, 2002).

Os resíduos do setor têxtil contêm impurezas físicas, químicas e biológicas, que são removidas das peças durante o processo de lavagem e tingimento (NAVACHI, 2002). Neste sentido, Bastos (2002) afirma que em face do real e potencial efeito 
poluidor dos efluentes das lavanderias se faz necessário garantir ações de redução de impactos ambientais deste processo produtivo.

Para Hassemer (2006), estes resíduos têxteis são tóxicos e sua má destinação resulta em impactos ambientais. Pode-se entender que a utilização de corantes compostos por metais pesados são uma das preocupações do processo de destinação destes efluentes, também pode-se destacar os resíduos sólidos como: fibras, fios e tecidos. Após o processo da lavagem têxtil é possível observar o nível de poluição pela textura, cor e alta turbidez dos efluentes (KUNZ et al., 2002).

Araújo (2015) analisou a forma de gerenciamento dos resíduos sólidos, com foco em restos de tecidos, das micro e pequenas empresas de confecções do Agreste de Pernambuco. Conclui que na atualidade, questões ambientais representam um dos problemas mais críticos e que os mesmos podem estar relacionados com a produção e consumo desenfreados.

Neste sentido, o autor afirma que a indústria de confecção, é um dos setores que mais destinam inadequadamente seus resíduos causando poluição ambiental e danos à saúde pública. O referido autor constatou que as empresas, não possuem políticas ambientais voltadas para o gerenciamento de seus resíduos e, as que possuem, só as têm para cumprir o que é exigido pela legislação, e não com responsabilidade socioambiental.

Corroborando com essa pesquisa, Guedes (2016) analisou os condicionantes da inovação nas micro e pequenas empresas de confecção de Santa Cruz do Capibaribe-PE. A amostra foi composta por 59 empresas de confecções. De acordo com tal pesquisa, $90 \%$ das empresas descartam os resíduos sólidos de forma inadequada e também observam que $42 \%$ das empresas destinam os resíduos no lixo comum.

\subsection{POSSIBILIDADES PARA SUSTENTABILIDADE AMBIENTAL NAS LAVANDERIAS DO SETOR TÊXTIL DE PERNAMBUCO}

No setor têxtil, as lavanderias ganham destaque pelo grande volume de água e produtos químicos utilizados nos processos produtivos, o que resulta em resíduos sólidos e líquidos. Estes resíduos quando são gerenciados de forma incorreta causam danos ambientais e sociais (ITABORAHY; SILVA, 2006; SILVA; SANTOS 2007). 


\section{¿unisul}

O processo produtivo das lavanderias têxteis do Agreste Pernambucano tem uma demanda expressiva de água. Segundo Lima (2006), para cada peça produzida, são gastos de 10 a 40 litros de água. Após a lavagem das peças, essas águas sem tratamento, em quase sua totalidade é despejada no rio.

O CPRH (2005) identificou que para fazer o processo de lavagem de jeans é necessário utilizam de 60 a 100 litros de água por peça o que pode entender que em média são 80 milhões de litros de água, por mês para atender a demanda da cidade de Santa Cruz do Capibaribe, a maior produtora de jeans do APL de confecções do Estado Pernambucano, e que maior parte desta água após uso no processo produtivo é destinada ao principal rio da cidade, Rio Capibaribe.

No entendimento de Navachi (2002), a maioria das lavanderias têxteis não contemplam no seu gerenciamento sistemas de gestão ambiental capazes de minimizar os impactos ambientais resultantes das etapas de produção. Assim, as lavanderias têxteis atuam no processo de beneficiamento do jeans através das etapas de lavagem nas quais utilizam produtos orgânicos, (amido, gomas, graxas, pectinas, álcoois, ácido acético, corantes, sabões e detergentes) e inorgânicos, (sódio, carbonatos, sulfetos e cloretos). Estes produtos são utilizados para modificar a cor, o brilho e a maciez do jeans (ITABOBOHY; SILVA, 2006, SILVA FILHO, 2013). Os resíduos contendo tais produtos quando são destinados para os rios, lagos e mar alteraram as propriedades químicas da água e reduziram o volume de oxigênio necessário para a vida aquática (SANTOS, 2006).

É sabido que essas lavanderias, têm por um lada papel importante para o Agreste do estado de Pernambuco, por gerar empregos e renda além de contribuir com beneficiamento das peças de jeans, e deixá-las mais competitivas no mercado nacional, por outro lado, causam impactos ambientais pelo alto grau de poluição de seus efluentes (SILVA FILHO, 2013).

Assim, faz-se necessário a adoção de processos ambientais pautados em ações da empresa para minimizar e/ou eliminar os efeitos negativos resultantes das atividades produtivas. Esses processos devem mobilizar os colaboradores a chegar a um patamar sustentável ideal.

\subsection{IMPACTOS AMBIENTAIS PROVOCADOS PELO SETOR TÊXTIL}


As ações produtivas do setor têxtil de Pernambuco têm provocado impactos ambientais visíveis no ar, nas águas e no solo fruto dos descontroles de emissão de elementos poluentes pelas empresas e das ações do ser humano, materializados na maneira de se relacionarem com o meio ambiente.

Como consequência dessas ações pode-se citar os impactos ambientais tais como: alterações climáticas, perdas de espécies e de habitats, poluição atmosférica, poluição dos lençóis freáticos entre outros.

Em consequência, foram criadas várias medidas para frear e/ou punir quem causar impacto negativos ao meio ambiente as quais achou-se sintetizadas na Lei 6.938/81, na referida lei, meio ambiente é o conjunto de condições, influências e interações de ordem física, química e biológica, que permite, abriga e rege a vida em todas as suas formas. Assim, deve-se preservar a atmosfera, as águas interiores, superficiais e subterrâneas, os estuários, o mar territorial, o solo, o subsolo, os elementos da biosfera, a fauna e a flora (BRASIL, 1981). A mesma concentração de meio ambiente é assumida pelo CONAMA- Conselho Nacional do Meio Ambiente através da sua resolução 306 de 2002.

De acordo com a Lei 9.605/98, Art. 54, a quem causar poluição hídrica ou atmosférica incidirá pena de reclusão de um a cinco anos. A lei 14.249/10 no seu Art. 40 considera infração administrativa ambiental toda ação ou omissão que resulte em poluição ou degradação ambiental. No Art. 42, afirma que os infratores devem reparar o dano ambiental causado e ficará sujeito a sanções civis e penais ou a multas que variam de $\mathrm{R} \$ 50,00$ a 50 milhões.

O Decreto Federal 97.632/89, por sua vez, afirma que a degradação é resultado de processos de danos ao meio ambiente, pelos quais se perdem ou se reduzem algumas de suas propriedades, tais como, a qualidade ou capacidade produtiva dos recursos ambientais" (BRASIL, 1989). Considerando essa afirmação, pode-se entender que a degradação ambiental é consequência das ações do homem ao usar os recursos renováveis de forma a torná-los inexistentes ou reduzindo sua capacidade de recuperação. Deste modo, qualquer processo que minimize a capacidade de manter a vida é chamado de degradação ambiental (HARRINGTON; KNIGHT,2001).

A Lei 9.985/2000 prevê que a degradação refere-se à deterioração ou perda total da capacidade para uso presente e futuro (Brasil, 2000). A NBR ISSO 14001 
(2004), determina que o impacto ambiental é qualquer alteração no meio ambiente, de forma adversa. O CONAMA, resolução 001 de 1986, é considerado impacto ambiental qualquer alteração das propriedades físicas, químicas e biológicas do meio ambiente, causada por qualquer forma de matéria ou energia resultante das atividades humanas que, direta ou indiretamente, afetam:

I - a saúde, a segurança e o bem-estar da população;

II - As atividades sociais e econômicas;

III - a biota;

IV - As condições estéticas e sanitárias do meio ambiente;

$\mathrm{V}$ - A qualidade dos recursos ambientais.

Ao IBAMA (Instituto Brasileiro do Meio Ambiente e dos Recursos Naturais Renováveis), órgão responsável pela execução das leis estabelecidas pelo CONAMA, cabe fiscalizar o patrimônio ambiental, promover ações de preservação, conservação, como também outorgar licenças ambientais às indústrias têxteis.

A OMS (Organização Mundial da Saúde), também, chama atenção para os danos causados pelas indústrias tanto na saúde humana como ambiental. Assim, a poluição do ar, que é resultante do lançamento de gases ou partículas líquidas e sólidas na atmosfera, provoca impacto ao meio ambiente e a saúde dos indivíduos, e nas lavanderias essa poluição é consequência da queima de lenha nas caldeiras.

Outra poluição que também ganha destaque no APL de confecções é a poluição hídrica, que é resultante do lançamento de rejeitos na água dos rios Ipojuca e Capibaribe, tal conduta do agente produtivo resulta em problema por interferir negativamente na manutenção da vida e no habitat de várias espécies. Outro tipo de consequência deste lançamento de efluentes nos rios é a eutrofização da água, que é quando ocorre uma proliferação de algas e cianobactérias, o que reduz a quantidade de oxigênio necessário para manter a vida das espécies aquática.

As lavanderias têxteis ao queimarem lenhas nas caldeiras, geram resíduos atmosférico e resíduos tóxicos durante seu processo produtivo, tais resíduos, quando destinados às redes pluviais sem tratamento, podem gerar poluição que compromete o meio ambiente de forma significativa (SAFT, 2014; LIMA, et al., 2016).

As empresas ao conhecerem os aspectos que causam os impactos ambientais proveniente de suas atividades contribuem para o bom desempenho ambiental 


\section{¿unisul}

(HENKELS, 2002). Dessa forma, impõe-se ações de educação ambiental para redução dos problemas ambientais decorrentes dos processos produtivos das lavanderias.

Para Silva e Santos (2007), por muitos anos, os danos ambientais ocasionados pelo lançamento de efluentes das indústrias têxtil com alto teor tóxicos nos rios, não foram considerados como um delito, apenas era questionado pelo impacto visual proporcionado pela cor que se modifica com a moda. Quanto a cor, a CONAMA na resolução 357 determina limites para a cor das águas como medida de qualidade, deixando claro que nenhum efluente ao ser lançado num corpo receptor poderá alterar suas propriedades de qualidade.

No estudo de Xavier (2006), ficou evidente que um dos problemas que impede o desenvolvimento da região é a indisciplina social através da depredação do meio ambiente e a poluição do Rio Capibaribe.

Oliveira (2007) por sua vez corrobora com afirmação de Xavier ao afirmar que as atividades das lavanderias industriais do setor de confecção têxtil do município de Toritama, vêm modificando o uso e a ocupação do solo e causando problemas ambientais ao rio Capibaribe, pelos lançamentos direto ou indiretamente, no rio, com reflexos na qualidade de vida da população local.

O estudo de Lopes (2011) verificou que a fase de beneficiamento do jeans convencional, processos produtivos das lavanderias, têm alto potencial de impacto ambiental e a saúde humana pois envolve substâncias altamente tóxicas.

Os riscos causados pelo processo produtivo das lavanderias causam danos à saúde do trabalhador, do meio ambiente e da população local, devido às emissões gasosas, mas principalmente dos efluentes que causam danos aos rios, solo e ar (BOTTOS, 2007; HEISE, 2009; KNOLL, 2011 e TAVARES, 2011, RODRIGUES 2012, POLLI, 2013).

Outro estudo sobre lavanderias industriais, chama atenção para os danos causados ao meio ambiente, ao entender que uma das fases do processo produtivo do jeans, a lavagem, exige muita água e muito combustível, a exemplo da queima de lenha (MATOS; BASTOS, MACHADO 2014).

A Agência Estadual de Meio Ambiente-CPRH (2005) afirmou que a poluição das lavanderias, não é só da água, mas também do ar e do solo. Neste sentido, pode-se 
entender que esta poluição, advinda dos processos produtivos, é consequência de as lavanderias não utilizarem, de forma estratégica, a gestão ambiental. Assim, os impactos ambientais provocados pelas lavanderias modificam as condições normais do funcionamento da natureza e causam danos irreversíveis ao mundo. De fato, inicialmente o impacto ocorre em escala local, e tem consequências em escala global.

\section{MATERIAL E MÉTODO}

Para alcançar os objetivos propostos, utilizou-se o método de revisão bibliográfica em base de dados de teses, dissertações e monografias, além, do google acadêmico para levantar artigos que abordassem o tema em análises. Para GarzaReyes (2015), este tipo de pesquisa propugna uma abordagem exata do tema analisado de forma reprodutiva e transparente.

Vale salientar que para atender ao objetivo da pesquisa foi preciso restringir as bases de dados, uma vez que, as buscas nas bases como SciELO não resultaram em estudos que tratassem do tema de forma primária ou secundária. Assim, a base de dados para realizar a pesquisa foi restringida pelo fato de o tema analisado ainda não ter ganhado grandes notoriedade nacional e internacional.

Após a escolha do método foi realizada a formulação da questão de pesquisa. Elegendo-se a elaboração dos critérios de inclusão e exclusão de estudos, também foi definido o instrumento para coleta de dados, avaliação e análise, interpretação e discussão dos resultados obtidos nos estudos selecionados.

Como critério de inclusão foi considerado as pesquisas que abordavam o arranjo produtivo de confecções do agreste, danos ambientais no município de Caruaru e/ou Toritama e/ou Santa Cruz, impactos ambientais no setor têxtil, poluição/qualidade do solo, da água e do ar dos municípios, além de estudos que abordam a qualidade da água do rio Capibaribe e Ipojuca, conforme Quadro 1.

Como critério de exclusão, foi excluído estudos que tratavam de aspectos ambientais positivo ou negativo em outra região do estado ou país, também foram excluídos estudos que falavam do arranjo produtivo local, porém, não abordavam questões ambientais, e por fim foram excluídos estudos que falavam de questões ambientais sem levantar os principais impactos relacionados com a atividade das lavanderias. 


\section{¿unisul sim}

Quadro 1 - Número de citações encontradas utilizando as palavras chaves

\begin{tabular}{|l|c|c|c|c|c|}
\hline & \multicolumn{4}{|c|}{ Palavras chaves } \\
\hline & $\begin{array}{c}\text { APL de } \\
\text { confecções do } \\
\text { agreste } \\
\text { Pernambucano }\end{array}$ & $\begin{array}{c}\text { Danos } \\
\text { ambientais } \\
\text { no município } \\
\text { de Caruaru } \\
\text { e/ou } \\
\text { Toritama } \\
\text { e/ou Santa } \\
\text { Cruz }\end{array}$ & $\begin{array}{c}\text { Qualidade da } \\
\text { água do rio } \\
\text { Capibaribe e } \\
\text { lpojuca }\end{array}$ & $\begin{array}{c}\text { Poluição no } \\
\text { solo, água e } \\
\text { ar no Arranjo } \\
\text { Produtivo }\end{array}$ & $\begin{array}{c}\text { Impactos } \\
\text { ambientai } \\
\text { s no setor } \\
\text { têxtil }\end{array}$ \\
\hline Estudos & 27 & 13 & 11 & & \\
\hline
\end{tabular}

Fonte: Autores, 2018.

Figura 1- Organograma dos estudos pesquisados

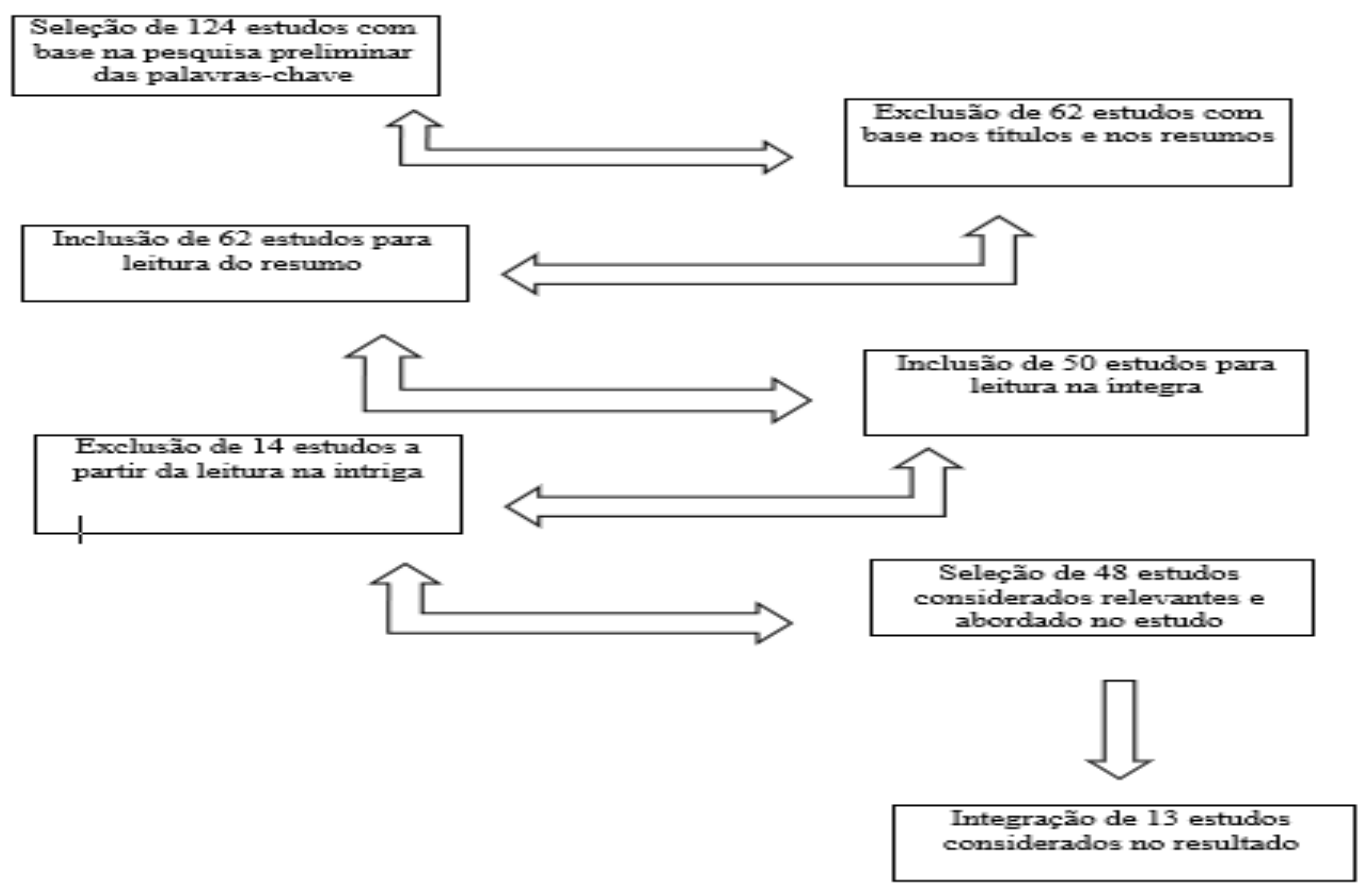

Fonte: Autores, 2018.

Como pode ser observado na Figura 1, inicialmente foram selecionados 124 estudos que pelo título indicavam tratar-se do tema estudado, em seguida foram excluídos 62 estudos por não abordar nenhuma das palavras chaves definidas com critério de inclusão.

Deste universo utilizou-se apenas 48 estudos correlacionaram pelo menos a uma das palavras chaves. Com a leitura do resumo e conclusão foram excluídos 35 estudos. Por fim foram selecionados 13 estudos que abordaram os impactos 


\section{¿unisul}

ambientais relacionados com as atividades das lavanderias do APL do Agreste Pernambucano.

Vale salientar que, também, foi usado no texto Leis que abordam as responsabilidades sobre o meio ambiente como o que explica o impacto ambiental na visão jurídica.

\section{RESULTADO E DISCUSSÃO}

As lavanderias têxteis do Arranjo Produtivo Local - APL de confecções do Agreste Pernambucano, é composta em média por 200 lavanderias sendo que o maior número delas encontra-se no município de Toritama, seguido de Caruaru, Riacho das Almas, Vertentes e Santa Cruz do Capibaribe.

Estas indústrias consome uma grande quantidade de água nos seus processos produtivos e também são responsáveis, em muitos casos, conforme Quadros 2 e 3, pelo lançamento de seus efluentes nos leitos dos Rios Capibaribe e Ipojuca sem adequados tratamentos, contribuindo de forma negativa para o aumento da poluição das águas o que impacta na qualidade de vida dos indivíduos e risco à saúde humana.

Os estudos sobre impactos ambientais ganharam destaque na região após a constatação pelo $\mathrm{CPRH}$, em 2005, de poluição no Rio Capibaribe como também outros impactos ambientais no meio ambiente em decorrência da atividade das lavanderias.

Assim, a partir de 2005, vários estudos corroboram com a pesquisa do órgão fiscalizador, a exemplo de Lima (2006) que concluiu que a maioria dos empresários (64\%) admite que começaram a se preocupar com o meio ambiente, somente, a partir da presença da $\mathrm{CPRH}$ e do Ministério Público na cidade. Sendo assim, foram levantados os principais impactos socioambientais a partir do processo produtivo das lavanderias conforme Quadro 2.

Quadro 2 - Principais impactos socioambientais

\begin{tabular}{|c|c|c|c|}
\hline Processo & Resíduo gerado & $\begin{array}{c}\text { Possíveis Impacto } \\
\text { ambientais }\end{array}$ & Possíveis impactos sociais \\
\hline Caldeira & Cinzas & Poluição atmosférica & Causa de doenças respiratórias \\
\hline
\end{tabular}




\section{¿unisul}

\begin{tabular}{|c|c|c|c|}
\hline Lavagem & $\begin{array}{l}\text { Efluentes tóxicos, } \\
\text { embalagem de } \\
\text { produtos } \\
\text { químico, fibras de } \\
\text { tecidos }\end{array}$ & $\begin{array}{c}\text { Contaminação do lençol } \\
\text { freático, poluição da água, } \\
\text { morte dos animais marinhos. }\end{array}$ & $\begin{array}{l}\text { Incapacidade de uso da água por } \\
\text { parte da indústria e da } \\
\text { população, incapacidade de } \\
\text { alimentação dos seres vivos que } \\
\text { dependem do rio tais como } \\
\text { (bovinos, equinos, suínos, entre } \\
\text { outros); produtividade agrícola, } \\
\text { pesca, contribuindo } \\
\text { negativamente com o } \\
\text { desenvolvimento da cidade. }\end{array}$ \\
\hline $\begin{array}{l}\text { Sistema } \\
\text { de } \\
\text { tratament } \\
\text { o de } \\
\text { efluentes }\end{array}$ & $\begin{array}{l}\text { Lodo biológico, } \\
\text { embalagens de } \\
\text { produtos } \\
\text { químicos. }\end{array}$ & Poluição da água e do solo & $\begin{array}{l}\text { Proliferação de algas e } \\
\text { cianobactérias, o que reduz a } \\
\text { quantidade de oxigênio } \\
\text { necessário para manter a vida } \\
\text { das espécies aquáticas. }\end{array}$ \\
\hline $\begin{array}{l}\text { Atividade } \\
\quad \text { s } \\
\text { Gerenciai } \\
\quad \text { s }\end{array}$ & $\begin{array}{c}\text { Embalagem; } \\
\text { papelão, plástico, } \\
\text { vidro, cartucho } \\
\text { de impressoras, } \\
\text { e papéis em } \\
\text { geral. }\end{array}$ & $\begin{array}{l}\text { Poluição do rio, solo, } \\
\text { entupimentos dos córregos }\end{array}$ & $\begin{array}{l}\text { Inundações, quando chove, a } \\
\text { água invade as casas causando } \\
\text { danos materiais aos moradores. }\end{array}$ \\
\hline
\end{tabular}

Fonte: Dados da pesquisa, 2018.

Outro ponto abordado sobre a atuação das lavanderias têxteis é o grande volume de energia utilizado durante seus processos produtivos, o que impacta ainda mais a poluição ambiental. Pode-se dizer que esses impactos são resultados dos efluentes contaminados por químicas utilizadas no beneficiamento do jeans (SILVA FILHO, 2013).

Os principais problemas abordados pelos autores referem-se a não utilização de filtros nas chaminés, que resulta em odor fétido. Falta de coleta seletiva de lixo, destinação incorreta das embalagens de produtos tóxicos, efluentes sem tratamento destinados para os rios através das redes pluviais conforme Quadro 2 e 3.

Agência Estadual de Meio Ambiente e Recursos Hídricos - CPRH tendo em vista os danos ambientais causados pelas lavanderias resolveu, no ano de 2005, fazer uma análise da água do rio Capibaribe em diferentes pontos, onde se concentra o maior número de lavanderias do APL de confecções do Agreste Pernambucano. As amostras foram analisadas quanto aos aspectos físico-químicos e biológicos, como pH, OD, DBO, Condutividade Elétrica, Cloreto, Turbidez, Fósforo, Cor, Cromo, Salinidade e Coliformes Fecais. E concluíram que existia alta concentração de Coliformes Fecais provenientes dos esgotos domésticos e baixos valores do Oxigênio Dissolvido (OD), bem como ficou evidente os danos causados ao rio, pelo alto volume 
de resíduos químicos indústrias e resíduos sólidos em suas margens, proveniente do lixo doméstico (CPRH, 2005).

Quadro 3 - Estudos concluíram que as lavanderias do Agreste Pernambucano resultam em impactos ambientais.

\begin{tabular}{|c|c|c|c|}
\hline $\begin{array}{l}\text { Autor/an } \\
\text { o }\end{array}$ & Objetivo e método & Base de dados & Impacto ambientais \\
\hline $\begin{array}{l}\text { Lima } \\
(2006)\end{array}$ & $\begin{array}{l}\text { Objetivo: analisar o } \\
\text { processo de lavagem } \\
\text { usado nas lavanderias } \\
\text { de jeans, identificar a } \\
\text { demanda de água e seu } \\
\text { destino final. Método: } \\
\text { pesquisa de campo em } \\
11 \text { lavanderias. }\end{array}$ & $\begin{array}{l}\text { Dissertação do } \\
\text { Mestrado } \\
\text { Profissional em } \\
\text { Gestão Pública } \\
\text { Para o } \\
\text { Desenvolvimento } \\
\text { do Nordeste, } \\
\text { UFPE }\end{array}$ & $\begin{array}{l}\text { Poluição ambiental pelo fato de as } \\
\text { lavanderias lançarem a céu aberto } \\
\text { fortes camadas de fumaça } \\
\text { cinzenta, provenientes das } \\
\text { chaminés das caldeiras, além de } \\
\text { grande quantidade de resíduos } \\
\text { sólidos e líquidos. }\end{array}$ \\
\hline $\begin{array}{l}\text { Oliveira } \\
(2007)\end{array}$ & $\begin{array}{l}\text { Objetivo: investigar a } \\
\text { percepção ambiental de } \\
\text { diferentes atores sociais de } \\
\text { Toritama (PE), no Agreste } \\
\text { do Estado, em relação ao } \\
\text { rio Capibaribe e a gestão } \\
\text { ambiental local. } \\
\text { Método: análise de } \\
\text { campo. }\end{array}$ & $\begin{array}{l}\text { Dissertação } \\
\text { programa Gestão } \\
\text { e Políticas } \\
\text { Ambientais } \\
\text { Geografia da } \\
\text { UFPE }\end{array}$ & $\begin{array}{l}\text { O rio Capibaribe é agredido de } \\
\text { várias formas: Recebe os } \\
\text { efluentes domésticos e industriais, } \\
\text { lixo, é assoreado, tem as suas } \\
\text { margens ocupadas irregularmente } \\
\text { e o seu curso é barrado, em } \\
\text { alguns trechos, índice crescente } \\
\text { de doenças respiratórias na } \\
\text { população da cidade, decorrentes } \\
\text { da poluição atmosférica, } \\
\text { provocada pelas lavanderias } \\
\text { locais, bem como doenças } \\
\text { causadas pelas condições das } \\
\text { águas do rio. }\end{array}$ \\
\hline $\begin{array}{l}\text { Oliveira } \\
2008\end{array}$ & $\begin{array}{l}\text { Objetivo: determinar os } \\
\text { parâmetros físico-químicos } \\
\text { das águas utilizadas e } \\
\text { produzidas por lavanderias } \\
\text { de jeans de diferentes } \\
\text { capacidades } \\
\text { Industriais do município de } \\
\text { Toritama. Método: Estudo } \\
\text { de caso em três } \\
\text { lavanderias en } \\
\text { de Toritama-PE. }\end{array}$ & $\begin{array}{c}\text { Dissertação } \\
\text { programa } \\
\text { engenharia Civil } \\
\text { da UFPE }\end{array}$ & $\begin{array}{l}\text { As lavanderias utilizam, em seus } \\
\text { processos, água de baixa } \\
\text { qualidade com elevados valores } \\
\text { de alumínio, nitrato, nitrogênio } \\
\text { amoniacal, cor verdadeira, } \\
\text { turbidez e contaminação dos } \\
\text { mananciais do rio Capibaribe, que } \\
\text { recebe os efluentes domésticos e } \\
\text { industriais. }\end{array}$ \\
\hline $\begin{array}{l}\text { Santos } \\
2012 .\end{array}$ & $\begin{array}{l}\text { Objetivo: avaliar o Arranjo } \\
\text { Produtivo Local (APL) de } \\
\text { Confecção de riacho das } \\
\text { Almas PE, a partir de } \\
\text { análises socioeconômica e } \\
\text { ambiental. Método: } \\
\text { estudos de casos }\end{array}$ & $\begin{array}{c}\text { Dissertação } \\
\text { programa de } \\
\text { gestão Pública, } \\
\text { UFPE }\end{array}$ & $\begin{array}{l}\text { Os resíduos gerados a partir do } \\
\text { processo de lavagem e tingimento } \\
\text { do jeans vão para o esgoto e lixo } \\
\text { comuns, poluindo os corpos } \\
\text { hídricos. Manuseio inadequado } \\
\text { das embalagens químicas nos } \\
\text { lixos comuns. }\end{array}$ \\
\hline $\begin{array}{l}\text { Silva } \\
\text { Filho } \\
(2013)\end{array}$ & $\begin{array}{l}\text { Objetivo: propor um } \\
\text { Sistema Simplificado de } \\
\text { Gestão Integrada para } \\
\text { Micro e Pequenas } \\
\text { Empresas (SSGIMPE), } \\
\text { tomando-se como base as } \\
\text { normas ISO } 14001 \text { e a } \\
\text { OHSAS 18.001 }\end{array}$ & $\begin{array}{l}\text { Tese (doutorado) } \\
\text { - UFPE, Centro } \\
\text { de Tecnologia e } \\
\text { Geociências, } \\
\text { Programa de Pós- } \\
\text { graduação em } \\
\text { Engenharia Civil. }\end{array}$ & $\begin{array}{l}\text { Alto consumo de água e a } \\
\text { consequente geração de efluentes } \\
\text { contaminados e, tratamento físico- } \\
\text { químico. Resíduos dos tecidos e } \\
\text { de materiais utilizados nas } \\
\text { operações, resíduos sólidos } \\
\text { produzidos pelo tratamento dos }\end{array}$ \\
\hline
\end{tabular}

Revista Gestão e Sustentabilidade Ambiental., v. 10, n. 3, p. 77-103, set. 2021. 


\section{sunisul}

\begin{tabular}{|l|l|c|l|}
\hline & Método: estudos de casos & & $\begin{array}{l}\text { efluentes (lodo), emissões } \\
\text { atmosféricas liberadas } \\
\text { pelos } \\
\text { produtos químicos e a queima de } \\
\text { lenha na caldeira (cinzas). }\end{array}$ \\
\hline $\begin{array}{l}\text { Ribeiro } \\
(2016)\end{array}$ & $\begin{array}{l}\text { Objetivo: verificar o } \\
\text { impacto ambiental das } \\
\text { lavanderias no agreste } \\
\text { pernambucano. } \\
\text { Método: estudos de casos }\end{array}$ & $\begin{array}{c}\text { Artigo de } \\
\text { conclusão de } \\
\text { Curso Geografia, } \\
\text { UEPB }\end{array}$ & $\begin{array}{l}\text { Dificuldade de tratar os efluentes, } \\
\text { poluição atmosférica (caldeira } \\
\text { sem filtros), degradação do solo, } \\
\text { falta de destinação do resíduo } \\
\text { sólido (lodo da ETE). }\end{array}$ \\
\hline $\begin{array}{l}\text { Maciel } \\
(2017)\end{array}$ & $\begin{array}{l}\text { Objetivo: analisar as } \\
\text { formas de atuação do } \\
\text { órgão ministerial em favor } \\
\text { da proteção do rio em } \\
\text { Caruaru, } \\
\text { dedutivo e explicativa. }\end{array}$ & $\begin{array}{l}\text { Monografia, curso } \\
\text { Direito, } \\
\text { ASCES/UNITA } \\
\text { Caruaru -PE }\end{array}$ & $\begin{array}{l}\text { As lavanderias, a companhia de } \\
\text { saneamento local e a população } \\
\text { são responsáveis pelo alto índice } \\
\text { de agentes poluentes, lançados } \\
\text { nos leitos do rio Ipojuca, gerando } \\
\text { sérios danos ambientais. }\end{array}$ \\
\hline
\end{tabular}

Fonte: Dados da pesquisa, 2018.

Lima (2006) realizou um estudo em 11 lavanderias do município de Toritama com objetivo de analisar o processo de lavagem usado nas lavanderias de jeans, identificar a demanda de água e seu destino final. O autor concluiu que todo o efluente produzidos nas lavanderias tiveram como destino final a principal bacia de drenagem da cidade: O Rio Capibaribe, que abastece a Barragem do Jucazinho, responsável direto pelo abastecimento d'água à população do Agreste Central e Setentrional.

Outra constatação é que os efeitos da poluição decorrente desses efluentes afetam também a área rural, pelo funcionamento de lavanderias de jeans. Assim, cerca de $70 \%$ dos efluentes industriais e sanitários eram descartados na rede pluvial; os combustíveis mais utilizados pelas empresas são a lenha e retraços de tecidos, representando 69,4\% e 29\% respectivamente; a maioria das empresas, cerca de $85 \%$, não possui sistema de tratamento da água (LIMA, 2006).

Santos (2006) desenvolveu um estudo em uma lavanderia industrial no município de Toritama que utiliza a água do rio Capibaribe na lavagem do jeans, a empresa processar cerca de 120.000 mil peças por mês, tratam seus efluentes por processos físico-químicos, reutiliza em média $60 \%$ da água. $O$ estudo identificou importantes características biodegradáveis e a tratabilidade do efluente. Esta indústria realiza o beneficiamento de sua própria confecção em jeans e brim e de terceiros.

Pode-se concluir, que a sustentabilidade do desenvolvimento socioeconômico era um grande desafio para todo o polo de confecções. Uma das dificuldades apontadas pelo autor, foi a minimização da quantidade de água captada do rio Capibaribe, o reuso da água, diminuir os impactos ambientais resultantes dos 
efluentes bruto das lavanderias, que na análise mostrou grande variações de carga orgânica, que aumenta com a quantidade produzida. Portanto, o tratamento físicoquímico implantado pelas lavanderias remove de $30 \%$ a $40 \%$ da carga orgânica, também foi alta concentração de cálcio, alumínio e magnésio, produtos utilizados para o tratamento físico-químico da água o que, torna-se um fato limitador para fazer o reuso da água em outros processos que não seja a lavagem do jeans.

Neste sentido, Oliveira (2007) realizou um estudo com base nos resultados do CPRH (2005) e questionou a população, sobre quais os principais responsáveis pelos impactos ambientais existentes no rio Capibaribe, as pessoas entrevistadas responderam o Governo do Estado e o Governo Municipal, destacando ainda os proprietários das lavanderias. Também pode-se constatar que o rio é agredido ao longo de toda sua extensão, sendo que tais danos são diferenciados de acordo com a localidade, assim os impactos foram: ocupação das suas margens, aterros, desmatamento da mata ciliar, lançamento de esgotos, de resíduos sólidos e industriais.

Neste sentido, os problemas ambientais causados ao rio Capibaribe, aumenta com os recebimentos dos efluentes das lavanderias o que dificulta a utilização da água pela população, além de tornar impossível a vida dos animais. Assim pode-se entender que os efluentes jogados no rio sem tratamento, aumentaram ainda mais a carga poluidora, que como popularmente é chamada a água do rio fica da cor da moda (OLIVEIRA, 2007).

Oliveira (2008) analisou parâmetros físico-químicos das águas utilizadas e produzidas por lavanderias de jeans de diferentes capacidades Industriais do município de Toritama, o método foi o estudo de caso em três lavanderias (pequeno, médio e grande porte) de Toritama-PE. Identificou que as indústrias têxteis utilizam, em seus processos, água de baixa qualidade com elevados valores de alumínio, nitrato, nitrogênio amoniacal, cor verdadeira, turbidez e DBO. Estes elementos podem ter origem na contaminação dos mananciais de abastecimento por efluentes industriais e domésticos, uma vez que parte da população não é atendida por sistema de esgotamento sanitário, lançado no rio seus efluentes domésticos, e as indústrias locais têm o rio Capibaribe como único corpo receptor dos efluentes das estações de tratamento de água - ETEs. O fato de as indústrias lançarem os efluentes no 
Capibaribe e captarem a jusante água desse mesmo corpo hídrico para utilização como insumo do processo produtivo caracteriza o reuso indireto.

No estudo de Santos (2012), foi percebido que os impactos ambientais iniciavam com o corte dos jeans que normalmente acontece nos fabricos e facções, depois continuava nos processos de lavagem, em decorrência do volume de água desperdiçado, bem como efluentes contaminados por produtos químicos, e a fumaça na atmosfera das caldeiras. O estudo também pode concluir que a poluição da água do rio, do solo e da atmosfera é resultado do processo produtivo das lavanderias.

Assim, os efluentes gerados contém substâncias orgânicas e inorgânicas, alteração de $\mathrm{pH}$, corantes e metais pesados, hidrocarbonetos e detergentes tensoativos. Portanto, os produtos químicos usados na lavagem e no tingimento do jeans, associado à falta da prática do uso de equipamentos de proteção individual, e o manuseio inadequado das embalagens são problemas encontrados dentro das lavanderias que envolvem riscos para a saúde humana e a degradação do meio ambiente (SANTOS, 2012).

Silva Filho (2013) realizou pesquisa com objetivo de propor um Sistema Simplificado de Gestão Integrada para Micro e Pequenas Empresas (SSGIMPE), tomando como base as normas ISO 14.001 e a OHSAS 18.001. Identificou que o alto consumo de água, geração de efluentes contaminados e, também, por possuir somente o tratamento físico-químico, são causas do impacto ambiental provocados pelos tratamentos dos tecidos e de materiais utilizados nas operações, resíduos sólidos produzidos pelo tratamento dos efluentes (lodo), emissões atmosféricas liberadas pelos produtos químicos e na queima de lenha na caldeira (cinzas).

Ribeiro (2016) em pesquisa, com objetivo de verificar o impacto ambiental das lavanderias no Agreste Pernambucano, analisou uma empresa de pequeno porte no município de Caruaru. Concluiu, que a lavanderia tem dificuldade de tratar os efluentes produzidos no processo produtivo, geram poluição atmosférica (resultante das caldeiras sem filtros), degrada o solo pela destinação incorreta dos resíduos contaminados por químicas, falta de destinação do resíduo sólido (lodo que é gerado pelo tratamento da água).

Maciel (2017) afirma que a poluição dos rios não é apenas das lavanderias, mas da companhia de saneamento local e a população que são responsáveis pelo 
alto índice de agentes poluentes, lançados nos leitos do rio Ipojuca, gerando sérios danos ambientais, como pode ser observado no gráfico.

Silva e Santos (2007), em estudo com 46 lavanderias, conforme Quadro 4, identificaram que $67 \%$ das lavanderias são abastecidas por carros Pipas $70 \%$ queima lenha, sendo uma das causas do desmatamento, também foi identificado que $30 \%$ têm como fonte secundária de energia a queima dos restos dos tecidos, também concluíram que $50 \%$ das indústrias têxtil utilizam para o controle de poluição atmosférica. $69 \%$ destinam seus efluentes sem tratamentos na rede pluvial, $16 \%$ da amostra deixa os efluentes a céu aberto.

A pesquisa de Silva e Santos (2007) relata que a maior parte das empresas fazem o tratamento com a utilização de cimento, tijolos, pedras, areia e material orgânico, ou seja, realizam um processo de filtragem arcaico, mas que atende às necessidades momentâneas.

Os autores concluíram que os parâmetros de responsabilidade ambiental era 0 lucro e que a maior preocupação estava voltada para evitar multas e punições fiscais e que o destino dos efluentes e dos dejetos sólidos são depositados, respectivamente, no Rio Capibaribe e no lixão da cidade de Toritama, sem qualquer tratamento, ou acondicionamento especial.

Quadro 4- estudos publicados em periódicos sobre impactos ambientais no APL

\begin{tabular}{|c|c|c|c|}
\hline Autor/ano & Objetivo e método & $\begin{array}{l}\text { Base de } \\
\text { dados }\end{array}$ & Impacto ambientais \\
\hline $\begin{array}{l}\text { Silva; } \\
\text { Santos } \\
(2007)\end{array}$ & 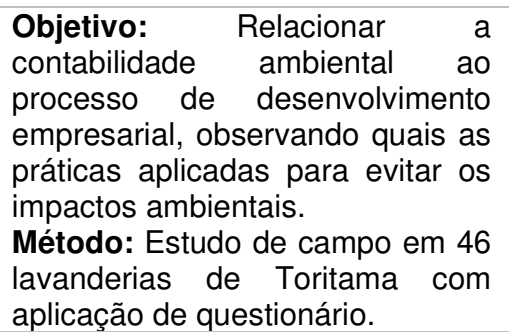 & $\begin{array}{l}\text { Anais de } \\
\text { evento }\end{array}$ & $\begin{array}{l}\text { Os relatórios ambientais são } \\
\text { praticamente inexistentes; efluentes } \\
\text { e os dejetos sólidos originários do } \\
\text { beneficiamento das peças em jeans } \\
\text { são depositados, respectivamente, } \\
\text { no Rio Capibaribe e no lixão da } \\
\text { cidade de Toritama. }\end{array}$ \\
\hline $\begin{array}{l}\text { Silva et al } \\
(2012)\end{array}$ & $\begin{array}{l}\text { Objetivo: traçar o perfil das } \\
\text { lavanderias de jeans no } \\
\text { Município de Caruaru sob o ponto } \\
\text { de vista ambiental, tendo como } \\
\text { fundamentação teórica os } \\
\text { instrumentos econômicos de } \\
\text { proteção do meio ambiente. } \\
\text { Método: pesquisa de campo com } \\
47 \text { lavanderias de Caruaru. }\end{array}$ & $\begin{array}{l}\text { Revista } \\
\text { Científica }\end{array}$ & $\begin{array}{l}40 \% \text { das lavanderias jogam seus } \\
\text { efluentes industriais no esgoto } \\
\text { público e } 38 \% \text { nos canais. Chama a } \\
\text { atenção a percentagem de efluentes } \\
\text { derramados no Rio Ipojuca }-18 \% \text { o } \\
\text { que causa uma degradação dos } \\
\text { recursos naturais do rio Ipojuca. }\end{array}$ \\
\hline
\end{tabular}




\section{sunisul}

\begin{tabular}{|c|c|c|c|}
\hline $\begin{array}{l}\text { Bezerra e } \\
\text { Freitas, } \\
(2013)\end{array}$ & $\begin{array}{l}\text { Objetivo: de avaliar as atividades } \\
\text { de uma lavanderia industrial na } \\
\text { cidade de Santa Cruz do } \\
\text { Capibaribe-PE, a luz da produção } \\
\text { mais limpa. } \\
\text { Método: Estudo de caso em uma } \\
\text { lavanderia. }\end{array}$ & $\begin{array}{l}\text { Anais } \\
\text { evento }\end{array}$ & $\begin{array}{l}\text { A falta de conhecimento dos } \\
\text { gestores, falta de estrutura } \\
\text { organizacional, e a falta de } \\
\text { interesses ambientais por parte da } \\
\text { organização são fatores que } \\
\text { contribuem para a poluição do rio } \\
\text { Capibaribe. }\end{array}$ \\
\hline $\begin{array}{l}\text { Brandão } \\
\text { (2017) }\end{array}$ & $\begin{array}{l}\text { Objetivo: analisar as Políticas } \\
\text { ambientais e seus instrumentos } \\
\text { enquanto interventores na relação } \\
\text { crescimento econômico e meio } \\
\text { ambiente nas lavanderias de } \\
\text { Toritama. } \\
\text { Método: estudo de caso. }\end{array}$ & $\begin{array}{l}\text { Revista } \\
\text { Científica }\end{array}$ & $\begin{array}{l}\text { O preço é o impacto no consumo } \\
\text { de recursos naturais e na produção } \\
\text { de resíduos, dentre outros. A } \\
\text { lavagem impacta com o consumo } \\
\text { de água e de lenha para } \\
\text { aquecimento de caldeiras, bem } \\
\text { como com a geração de efluentes, } \\
\text { de poluição atmosférica e de } \\
\text { resíduos sólidos e industriais. }\end{array}$ \\
\hline $\begin{array}{l}\text { Viana et al } \\
(2018)\end{array}$ & $\begin{array}{l}\text { Objetivo: avaliar a Pegada Hídrica } \\
\text { Azul - PHA do processo de } \\
\text { beneficiamento do jeans em } \\
\text { quatro lavandarias têxtil } \\
\text { localizadas no Polo de Confecções } \\
\text { do Agreste de Pernambuco. } \\
\text { Método: Estudo descritivo em } 04 \\
\text { lavanderias. }\end{array}$ & $\begin{array}{l}\text { Revista } \\
\text { Científica }\end{array}$ & $\begin{array}{l}\text { O processo de beneficiamento têxtil } \\
\text { é um significativo potencial poluidor } \\
\text { devido ao elevado volume de água } \\
\text { necessário para o seu processo } \\
\text { produtivo e que o reuso e o correto } \\
\text { manejo das águas residuais podem } \\
\text { funcionar como alternativas } \\
\text { mitigadoras. }\end{array}$ \\
\hline $\begin{array}{l}\text { Lorena et } \\
\text { al., (2018) }\end{array}$ & $\begin{array}{l}\text { Objetivo estabeleceram um } \\
\text { modelo de gestão de riscos em } \\
\text { lavanderias de beneficiamento no } \\
\text { APL têxtil e de confecções do } \\
\text { Agreste de Pernambuco. } \\
\text { Método: Estudo de caso em } 04 \\
\text { lavanderias }\end{array}$ & $\begin{array}{l}\text { Revista } \\
\text { Científica }\end{array}$ & $\begin{array}{l}\text { Os riscos ambientais inerentes ao } \\
\text { processo de lavagem em } \\
\text { beneficiamento têxtil são: a } \\
\text { contaminação nos corpos hídricos, } \\
\text { no solo e no ar; além de } \\
\text { desequilíbrio no ecossistema, por } \\
\text { desmatamento da flora nativa. }\end{array}$ \\
\hline
\end{tabular}

Fonte: Dados da pesquisa, 2018.

Silva et al., (2012) realizaram uma pesquisa para traçar o perfil das lavanderias de jeans no Município de Caruaru sob o ponto de vista ambiental, tendo como fundamentação teórica os instrumentos econômicos de proteção do meio ambiente. Como método foi a pesquisa de campo com 47 lavanderias. Os autores identificaram que $40 \%$ dos efluentes líquidos são despejados no esgoto público do município, 38\% nos canais e $18 \%$ diretamente no Rio Ipojuca; mais de $60 \%$ das lavanderias não possui mudança tecnológica que vise reduzir os impactos ambientais, o que vem contribuindo para a degradação dos recursos naturais do município e dos demais 47 municípios que o rio corta ao longo da sua trajetória até chegar ao mar.

Bezerra e Freitas (2013) realizaram um estudo com objetivo de avaliar as atividades de uma lavanderia industrial na cidade de Santa Cruz do Capibaribe-PE, a luz da produção mais limpa. Identificou que um dos entraves é a falta de conhecimento dos gestores quanto às formas de aproveitamento e destinação adequada do lodo gerado no tratamento de efluente industrial, outra barreira é a estrutura organizacional 
inadequada e sistema de informação incompleto; acesso limitado à informação; desconhecimento dos custos ambientais.

Assim, pode-se concluir que as lavanderias industriais do Agreste de Pernambuco contribuem enormemente para a degradação ambiental, sobretudo, do rio Capibaribe/PE. Os autores concluíram, que apesar da suma importância do setor, não existem interesses ambientais por parte da organização, ao entender, que não existem ações de reuso da água ou minimização da quantidade usada, uso de produtos menos agressivos ao meio ambiente; equipamentos mais eficientes em termos de insumos (água, lenha, alvejantes, amaciantes) e em termos de rejeitos (calor, vapor, resíduos).

Outro estudo que confirma estes resultados é o de Brandão (2017), que trabalhou com 56 lavanderias têxtil de jeans no município de Toritama. O autor concluiu que as indústrias contribuem para o crescimento econômico da região, porém tem causado danos a natureza pelo consumo dos bens naturais como água e lenha, e na produção e destinação dos efluentes e resíduos sólidos, também constatou que as lavanderias têm causado a poluição atmosférica pela queima de lenha nas caldeiras.

Viana et al., (2018) avaliaram a Pegada Hídrica Azul - PHA do processo de beneficiamento do jeans em quatro lavandarias têxtil localizadas no Polo de Confecções do Agreste de Pernambuco. As mesmas apresentaram PHA de 17.74, 24, 14.93 e 60 litros por peças, respectivamente. Os autores concluíram que o conhecimento da pegada hídrica do processo de beneficiamento têxtil mostrou que essa atividade é caracterizada como de significativo potencial poluidor devido ao elevado volume de água necessário para o seu processo produtivo e que o reuso e o correto manejo das águas residuais podem funcionar como alternativas mitigadoras.

Lorena et al. (2018), em seu estudo estabeleceu um modelo de gestão de riscos em lavanderias de beneficiamento no APL têxtil e de confecções do Agreste de Pernambuco. A análise foi realizada em quatro lavanderias dos municípios de Caruaru, Toritama, Riacho das Almas e Santa Cruz do Capibaribe. Identificaram que existem riscos ambientais inerentes ao processo de lavagem e beneficiamento têxtil ao entender que o processo produtivo gera contaminação nos corpos hídricos, no solo e no ar; além de desequilíbrio no ecossistema, por desmatamento da flora nativa. 
Também foi possível identificar problemas sociais relacionados à exposição dos trabalhadores ao subemprego, além do risco à saúde. Entre os riscos apontados na pesquisa, destaca-se: riscos de impactos ecológicos (51\%), risco de segurança humana $(44,6 \%)$ riscos de processo gerencial $(5,4 \%)$, ricos no 'processo de lavagem, os riscos relacionados a geração de vapor foram considerados incidência de riscos $(45,3 \%)$, ao entender que as caldeiras é potencial poluidor além de representar risco a segurança do trabalhador.

\section{CONSIDERAÇÕES FINAIS}

O APL de confecções do agreste de Pernambuco, tem um grande desafio que é o abastecimento de água, onde grande parte das casas, indústrias e empresas são abastecidas por carros-pipa em diversos períodos do ano. E de acordo com os estudos apresentaram elevados níveis de poluição devido às atividades poluidoras do APL de confecções do Agreste.

A qualidade da água conduzida pelos carros pipas é inadequada, colhida dos rios de rejeição. Outro fator que ganha destaque no nível de poluição é a queima da lenha que é um dos principais elementos da poluição atmosférica. Além disso, os produtos químicos utilizados nas rotinas diárias das lavanderias são responsáveis pela poluição hídrica e do solo.

Este estudo teve como objetivo levantar os impactos ambientais originados pelas lavanderias têxteis do APL de confecções do Agreste Pernambucano. O método para levantamento de dados foi a revisão sistemática. Pode-se dizer que a geração de efluentes no processo produtivo das lavanderias é um forte limitador do desenvolvimento sustentável no APL de confecções do agreste.

De acordo com os estudos levantados a poluição atmosférica é resultado da fumaça liberada pelas caldeiras, além do despejo indiscriminado dos resíduos industriais no Rio Capibaribe, como detergentes, amaciantes e outros produtos químicos, despontando como o principal responsável pela contaminação do único manancial da região. Pode-se entender que o rio Capibaribe é um dos meios receptores dos resíduos tóxicos; outra questão preocupante é a poluição atmosférica 
resultante da queima de lenha, poluição do solo e destinação dos resíduos sólidos para os lixos comuns.

Esta pesquisa teve como fator limitador a quantidade de estudos publicados em periódicos que abordam os impactos ambientais referente a atuação das lavanderias no APL de confecções do Agreste. Portanto, ao entender a importância do desenvolvimento sustentável, recomenda-se a realização de novas pesquisas sobre o impacto da atuação das lavanderias no meio socioambiental e na manutenção da vida, nestes municípios.

\section{REFERÊNCIAS}

ARAÚJO, W.C. "Análise do gerenciamento dos resíduos sólidos gerados pela Indústria de Confecções do Agreste de Pernambuco". 2015. Dissertação (Mestrado em Engenharia de Produção). Universidade Federal de Pernambuco, Recife, Pernambuco, 2015.

BASTOS, A.L.A. Modelo de apoio à seleção de produtos baseado na performance ambiental e nos objetivos estratégicos da organização. 2002. Dissertação (Mestrado em Engenharia de Produção e Sistemas). Universidade Federal de Santa Catarina/UFSC, Florianópolis, Santa Catarina, 2002.

BERARDI, P. C.; BARBIERI, J. C. Isomorfismos como motivadores da evolução da gestão ambiental: um estudo com médias e grandes empresas de dois estados brasileiros. Anais do XXXVII Encontro Nacional da Anpad. Rio de Janeiro, 2013.

BEZERRA, A. S.; FREITAS, L. S. Avaliação das atividades de uma lavanderia industrial à luz da produção mais limpa no polo de confecções de Santa Cruz do Capibaribe - PE. Anais. XVI SEMEAD Seminários em Administração, 2013.

BOTTOS, G.M. Marcação a laser. Semana de ensino, pesquisa e extensão. Anais. Universidade Federal de Santa Catarina, Florianópolis, Santa Catarina, 2007.

BRANDÃO, A. L. Instrumentos de política ambiental em Pernambuco: o caso das lavanderias de Toritama. Revista Científica Multidisciplinar Núcleo do Conhecimento. Ano 02, v. 1. p. 421-445, 2017.

BRASIL LEI 9.985/ 2000 Institui o Sistema Nacional de Unidades de Conservação da Natureza - SNUC, estabelece critérios e normas para a criação, implantação e gestão das unidades de conservação. Disponível em: <http://www.planalto.gov.br/ccivil_03/LEIS/L9985.htm>Acesso em 03/11/2018. 
BRASIL, LEI 12.305/2010. Institui a Política Nacional de Resíduos Sólidos; altera a Lei no 9.605, de 12 de fevereiro de 1998; e dá outras providências. Disponível em < http://www.mma.gov.br/port/conama/legiabre.cfm?codlegi=636> acesso em 18 out. 2010.

BRASIL, Lei no 9.605 de 12/02/1998. Dispõe sobre as sanções penais e procedimentos. Dispõe sobre critérios básicos e diretrizes gerais para a avaliação de impacto ambiental.

Providências. Disponível em: < http://www.planalto.gov.br/ccivil_03/leis//9605.htm>. Acesso em: 27 out. 2018.

BRASIL, Resolução CONAMA nº 1/1986. Licenciamento Ambiental - sobre critérios básicos e diretrizes gerais para a avaliação de impacto ambiental. Disponível em http://www2.mma.gov.br/port/conama/legislacao/CONAMA_RES_CONS_1986_001. pdf

BRITO, G. A. Sustentabilidade: um desafio para as lavanderias industriais. Rio de Janeiro, Revista REDIGE, v. 4, n. 2, 2013.

COSTA, A. F. de S. Aplicação de tratamentos de efluentes biológicos e físicoquímicos em efluentes de lavanderia e tinturaria industriais do município de Toritama no estado de Pernambuco. 2008, Dissertação (Mestrado em desenvolvimento ambiental). Universidade Católica de Pernambuco, Recife, Pernambuco, 2008.

FREIRE, R. S.; PELEGRINI, R.; KUBOTA, L. T.; DURAN, N.; PERALTA-ZAMORA, P. Novas tendências para o tratamento de resíduos industriais contendo espécies organocloradas. São Paulo, Revest Quamina Nova, v. 23, n. 4, p. 504- 511, 2000.

GARZA-REYES, J.A., Green lean and the need for Six Sigma. Int. J. Lean Six Sigma, v. 6, p.226-248, 2015.

GUEDES, R. E. F. de F. Condicionantes da inovação em empresas do arranjo produtivo de confecção em Santa Cruz de Capibaribe-PE. Dissertação, P. Administração e Desenvolvimento Rural, Recife, 2016 da Universidade Federal Rural de Pernambuco- UFRPE.

HARRINGTON, H. J.; KNIGHT, Al. A implementação da ISO 14000: como atualizar o SGA com eficácia. São Paulo: Atlas, 2001.

HASSEMER, M. E. N.; SENS, M. L. Tratamento do efluente de uma indústria têxtil. Processo físico-químico, ozônio e coagulação/floculação. Revista Engenharia Sanitária e Ambiental, v.7, n.1, 2002.

HEISE, C. Opção ecológica para desbotar tecidos. São Paulo, Textília, n. 71, p. 302009. 
IMMICH, A. P. S. Remoção de corantes de efluentes têxteis utilizando folhas de azadirachta indica como adsorvente. 2006, Dissertação (Mestrado em Engenharia Química). Universidade Federal de Santa Catarina, Florianópolis, Santa Catarina, 2006.

ITABORAHY, M.A.; SILVA, V.H. Indústrias de confecção no município de Cianorte-PR e a necessidade de implantação de programas de Gestão Ambiental. Revista Ciências Empresariais, v.12, n. 1, p.360-387, 2006.

JOHANSSON, G., SUNDIN, E. Lean and green product development: two sides of the same coin?. Journal of Cleaner Production, v.85, p.104-121, 2014.

KIPERSTOK, A.; COSTA, D. P.; ANDRADE, J. C.; AGRA FILHO, S.; FIGUEROA, E. Prevenção da poluição. Brasília: SENAI/DN, 2002 a. 290p.

KNOLL, K.C. Estonagem ecológica para denim. Revista Textília, v.1, n. 80, p. 30-24, 2011.

KON, Anita; COAN, Durval Calegari. Transformações da indústria têxtil brasileira: a transição para a modernização. Revista de economia Mackenzie, v. 3, n. 3, 2009.

KUNZ, A.; ZAMORRA, P. P.; MORAES, S. G. de; DURÁN, N. Novas tendências no tratamento de efluentes têxteis. São Paulo, Revista Química Nova, v. 25, n.1, pp.7882, 2002.

LIMA, H. S. As lavanderias de jeans de Toritama: Uma contribuição para a gestão das águas. Recife, UFPE, 2006 Dissertação (Programa de Pós-Graduação em Gestão e Pública p/ o Desenvolvimento do Nordeste).

LIMA, L. R. de; SAMPAIO, Y. de S. B.; FREITAS, M. A. L. de; LAGIOLA, U. C. T. Um estudo inferencial dos custos ambientais e das estações de tratamento de água nas lavanderias do Polo de confecções do Agreste de Pernambuco. Rio de Janeiro. Revista Sociedade, Contabilidade e Gestão, v. 11, n. 3, 2016.

LOPES, C. S. D. Análise ambiental da fase de acabamento do jeans. São Paulo, Revista de Saúde, Meio Ambiente e Sustentabilidade. v. 6, n. 3, p. 87-102, 2011.

LORENA, E. M. G.; LORENA, C. M. G.; MEDEIROS, R. M.; EL-DEIR, S. G.; HOLANDA, R. M.; ARAUJO, V. D. Modelo de gestão de riscos em lavanderias de beneficiamento no arranjo produtivo local (APL) têxtil e de confecções de Pernambuco, Brasil. Revista Produção Online. Florianópolis, SC, v. 18, n. 2, p. 620640, 2018.

MACIEL, E. de V. A poluição do rio Ipojuca no município de Caruaru e a intervenção do ministério público de Pernambuco. Monografia, (Bacharelado em Direito) Centro Universitário Tabosa de Almeida - ASCES/UNITA, Caruaru, Pernambuco 2017. 
MATOS, F. R. N.; BASTOS, A. T.; MACHADO, D. de Q. Desenvolvimento local no agreste pernambucano: uma "utopia possível". Campo Grande - MS, Revista INTERAÇÕES, v. 15, n. 1, p. 147-157, 2014.

MAZZA, C. L. de S.; FILHO, A. I. da S. Capacidades dinâmicas e sistemas de gestão ambiental: estudo da implementação da ISO 14001 no Laboratório Sabin. Rio de Janeiro. Anais XXXVII Encontro Nacional da Anpad, 2013.

MEHLER, J. R. Desafios da indústria têxtil e as demandas de sustentabilidade. Aquidauana/ MS, Revista Diálogos Interdisciplinares, v. 2, n. 2, p. 1-25, 2013.

NAVACHI, J.A. Reutilização dos efluentes tratados: caso de uma lavanderia industrial. 2002. Dissertação (Instituto de Engenharia Ambiental). Universidade Regional de Blumenau, Blumenau, Santa Catarina, 2002.

OLIVEIRA, F. P.; Percepção Ambiental e Gestão do Meio Ambiente de Toritama (PE) - estudo da percepção de diferentes atores sociais sobre o Rio Capibaribe. 2007, Dissertação (Mestrado em Gestão e Políticas Ambientais). Universidade Federal de Pernambuco, Recife, Pernambuco, 2007.

OLIVEIRA, O. J. de, SERRA, J. R. Benefícios e dificuldades da gestão ambiental com base na ISO 14001 em empresas industriais de São Paulo. Rio de Janeiro, Revista Produção, v. 20, n. 3, p. 429-438, 2010.

OLIVEIRA, R. G. Caracterização das águas e efluentes em lavanderias de jeans no agreste pernambucano, 2008. Dissertação (Programa de Pós-Graduação em Engenharia Civil). Universidade Federal de Pernambuco, Recife, Pernambuco, 2008.

PELIZER, L. H.; PONTIERI, M. H.; MORAES, I. de O. Utilização de resíduos agroindustriais em processos biotecnológicos como perspectiva de redução do impacto ambiental. Santiago, Chile. Journal of Technology Management \& Innovation, v 2, p. 118-127, 2007.

PERNAMBUCO. (Estado). Instrução Normativa CPRH № 004/2012. Disciplina o enquadramento para Licenciamento Ambiental na $\mathrm{CPRH}$ das atividades de Comércio e Serviço, quanto ao Potencial Degradador, conforme previsto no item 6.1 da Tabela 6 do Anexo I, da Lei Estadual nํ 14.249, de 17/12/2010 alterada pela Lei Estadual no 14.549, de 21/12/2011. Disponível em:

POLLI, A. Gerenciamento de impactos ambientais em lavanderias têxteis. Pombal PB, Revista brasileira de Gestão Ambiental GVAA - grupo verde de agroecologia e abelhas-. V. 7, n. 2, p. 12 - 18, 2013.

RIBEIRO, W. B. A. Estudo de caso sobre o impacto ambiental causado por uma lavanderia de jeans na cidade de Caruaru-PE. 2016, Monografia (Cursos de Geografia). Universidade Estadual da Paraíba, Campina Grande, Paraíba, 2016. 
RODRIGUES, E. F; FORMIGONI, A; DELIBERADOR, R.; TSUJ, E. R.; ALENCAR, S. R. A interferência do arranjo físico nas operações de uma lavanderia Industrial. Rio de janeiro, Anais IX SEGT Simpósio de gestão e tecnologia, 2012. Disponível em https://www.aedb.br/seget/arquivos/artigos12/59916745.pdf>acesso em 22/06/2018

SAFT, G. K.; CALHEIRO, D. Avaliação ambiental de processos de lavagem de roupas em uma lavanderia industrial. São Leopoldo/RS, Anais.5ำ fórum internacional de resíduos sólidos, 2014.

SAIDELLES, A. P. F.; SENNA, A. J. T.; KIRCHNER, R.; BITENCOUT G. Gestão de resíduos sólidos na indústria de beneficiamento de arroz. REGET/UFSM, Revista Eletrônica em Gestão, Educação e Tecnologia Ambiental. v.5, n. 5, p. 904 - 916, 2012.

SANTOS, J. J. Avaliação do arranjo produtivo local de confecção no município de Riacho das Almas no estado de Pernambuco. 2012. Dissertação, (Programa de Gestão Pública). Universidade Federal de Pernambuco, Recife, Pernambuco, 2012.

SANTOS, O. E. Caracterização, biodegradabilidade e tratabilidade do efluente de uma lavanderia industrial. 2006. Dissertação (Programa de Pós Graduação em Engenharia Civil). Universidade Federal de Pernambuco, Recife, Pernambuco, 2006.

SILVA FILHO, A. R. A. da. Desenvolvimento de sistema simplificado de gestão ambiental aplicado a micro e pequenas empresas de beneficiamento de jeans. 2013. Tese (doutorado) - UFPE, Centro de Tecnologia e Geociências, Programa de Pós-graduação em Engenharia Civil), Universidade Federal de Pernambuco, Recife, Pernambuco, 2013.

SILVA, A. N.; ALMEIDA, H. A. Diagnóstico do uso e reuso da água nas lavanderias têxtil de Toritama, PE. Campina Grande-PB, Anais do II congresso internacional da diversidade do semiárido. 2018. Disponível em $<$ https://editorarealize.com.br/revistas/conidis/trabalhos/TRABALHO EV074 MD1 S A5 ID1321 13102017211945.pdf> acesso em 22/06/2018

SILVA, M.V. A.; SILVA, A. L. da; BRITO, D. J. M. de; BRANCO, D. K. S.; FERREIRA, $\mathrm{M}$. de O. A questão Ambiental no polo de confecções em Caruaru: um primeiro ensaio à luz dos instrumentos econômicos de proteção ambiental. Revista de Estudos do CEPE, Santa Cruz do Sul, n.35, p.108-132, 2012.

SILVA, M. D. de O. P.; SANTOS, M. M. dos. A contabilidade ambiental nas lavanderias do setor têxtil de Toritama - Pernambuco. João Pessoa - PB, Anais... XIV Congresso Brasileiro de Custos - Brasil, 05 de dezembro a 07 de dezembro de 2007.

TAVARES, M.; ARNT, R. Velha, azul, desbotada e poluente. Revista Planeta, v.462, n.39, p. $32-42,2011$. 


\section{sunisul sim}

VIANA, M. A.; LIRA, E. B. de S., COELHO, C. de P. G.; BEZERRA, A. P. X. de G.; LORENA, E. M. G.; HOLANDA, R. M. de. Pegada hídrica em indústria de beneficiamento de jeans no Agreste Pernambucano. Recife - PE, UFRPE, Journal of Environmental Analysis and Progress, v. 03 n. 01, p. 061-068, 2018.

XAVIER, M. G. P. O processo de produção do espaço urbano em economia retardatária: a Aglomeração Produtiva de Santa Cruz do Capibaribe (1960-2000). 2006, Tese (Doutorado em Ciências Sociais). Universidade Federal de Pernambuco, Recife, Pernambuco, 2006. 